\title{
POLÍTICAS SOCIAIS E DIREITOS SOCIAIS NO BRASIL ${ }^{1}$
}

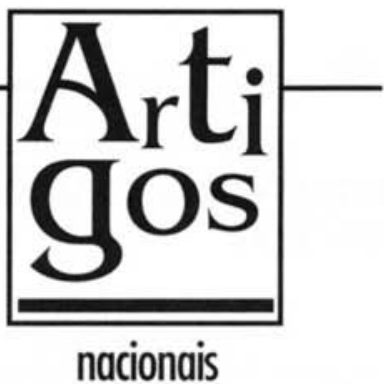

\section{Políticas sociais e direitos sociais no Brasil mudam ao sabor e ao ritmo das mudanças constitucionais, prática política subordinada às classes dirigentes, regidas pelos interesses externos}

Atualmente, não basta criticar a política social. É fundamental realizar a crítica da sua crítica, que quase sempre despreza a realidade e até a legitima pelo avesso. Quer dizer: ao desconhecer a realidade, confirma-a.

As reformas constitucionais fazem parte do costume político mais ou menos presente no Brasil depois de 1830, durante o Império, convertendo-se em tema obrigatório na República, sobretudo a partir da década de 1920: Reforma Constitucional em 1926, Revolução Constitucionalista em 1932 e Constituições de 1934, de 1937 (outorgada), de 1946, de 1967, de 1969 (outorgada com o Ato Institucional n.5) e de 1988.

Como classe historicamente cada vez mais subordinada, a classe dirigente no Brasil tem oscilado entre a inércia e a modernização imposta de fora, entre a promulgação de uma Constituição e a imediata proclamação de sua reforma. Assim, cada novíssima Constituição sempre surge atrasada, porque a classe dirigente exige sempre outras regras, diferentes daquelas que the eram aceitáveis ou favoráveis há pouco tempo, justificando-se com a necessidade de manter a estabilidade ou o crescimento do País.
A política social percorre dois momentos políticos distintos e marcantes do século $\mathrm{XX}$ no Brasil: escrevendo sobre tal assunto anos atrás ${ }^{2}$, afirmo que o "primeiro período de controle da política" corresponde à ditadura de Getúlio Vargas e ao populismo nacionalista, com influência para além de sua morte, em 1954. O "segundo período de política do controle" cobre a época da instalação da ditadura militar em 1964 até à conclusão dos trabalhos da Constituinte de 1988.

Nesses dois períodos, a política social brasileira compõe-se e recompõe-se, conservando em sua execução o caráter fragmentário, setorial e emergencial, sempre sustentada pela imperiosa necessidade de dar legitimidade aos governos que buscam bases sociais para manter-se e aceitam seletivamente as reivindicações e até as pressões da sociedade.

\section{AUTOR}

\section{Evaldo Amaro Vieira}

Professor Titular Doutor em Sociologia da Educação. Chefe do Departamento de Filosofia da Educação e Ciências da Educação, da Faculdade de Educação da USP. 


\section{POLÍTICA SOCIAL SEM DIREITOS SOCIAIS}

A partir de 1988, a política social acha-se no seu terceiro período de existência no Brasil, que chamo de "política social sem direitos sociais".

Em nenhum momento a política social encontra tamanho acolhimento em Constituição brasileira como acontece na Constituição de 1988 (Artigos $6^{\circ}, 7^{\circ}, 8^{\circ}, 9^{\circ}, 10^{\circ}$ e 11): nos campos da educação (pré-escolar, fundamental, nacional, ambiental etc.), da saúde, da assistência, da previdência social, do trabalho, do lazer, da maternidade, da infância e da segurança, definindo especificamente direitos dos trabalhadores urbanos e rurais, de associação profisssional ou sindical, de greve, de participação de trabalhadores e empregadores em colegiados dos órgãos públicos e de atuação de representante dos trabalhadores no entendimento direto com empregadores. O Capítulo II do Título II (Dos Direitos e Garantias Fundamentais) alude aos direitos sociais pertencentes à Constituição de 1988.

Poucos desses direitos estão sendo praticados ou ao menos regulamentados quando exigem regulamentação. Porém o mais grave é: em nenhum momento histórico da República brasileira (para só ficar nela, pois o restante consiste no Império escravista) os direitos sociais sofrem tão clara e sinceramente ataques da classe dirigente do Estado e dos donos da vida em geral como depois de 1995.

Esses ataques aos direitos sociais - em nome de algo que se pode intitular de "neoliberalismo tardio", em nome da "modernização" ou simplesmente em nome de nadaalimentam-se, no campo da política social, de falsas polêmicas. Vejam-se algumas delas, com brevidade:

a) A esquematização do desenvolvimento capitalista:

1. O capitalismo liberal correspondendo à racionalidade, à modernidade, ao Estado mínimo e ao Estado protetor;

2. O capitalismo organizado correspondendo ao racionalismo, à modernização e ao Estado-Providência;

3. O capitalismo desorganizado correspondendo à racionalização, à modernização, às transformações do Estado e da vida coletiva pela desregulação, pela convencionalidade e pela flexibilidade etc.

Tal esquematização ${ }^{3}$, que mais se assemelha a tipos ideais sem teoria, parece realçar principalmente traços organizativos do capitalismo. Despreza o processo histórico e esquece que o capitalismo, dos anos $70 \mathrm{em}$ diante, está em nova fase de acumulação, decorrente da revolução tecnológica, responsável por outro tipo de industrialização.

Ficam perguntas: por exemplo, para os objetivos pretendidos por esta nova fase do capitalismo, ele é mesmo desorganizado? Ou então: não existe historicamente certo grau de desorganização no capitalismo, apontado por exemplo pela necessidade de conservar parte dos trabalhadores em situação de desemprego?

b) Geralmente, as análises relacionadas com a política social se debatem na falsa contraposição entre neoliberalismo e social-democracia. Ou, o mais sério, elas contrapõem o que chamam de política social neoliberal à política social de cunho social-democrata. Fazem uma tipologia dos Estados, fixando a oposição 
entre Estado de bem-estar liberal e Estado de bem-estar social-democrata, para em seguida, por vezes, admitir o surgimento de nova fase da acumulação capitalista ${ }^{4}$.

Tais análises maniqueístas - que confrontam o Estado de bem-estar liberal com o Estado de bem-estar social-democrata, ou então a política social neoliberal com a polí- tica social de cunho social-democrata mostram o limite das possibilidades nelas contidas, reduzindo o futuro imediato da história à social-democracia. Mas o Estado de bem-estar social-democrata unicamente se manifesta ou se manifestará nos países desenvolvidos, no centro do capitalismo. Mesmo assim, nada além da social-democracia no futuro histórico.

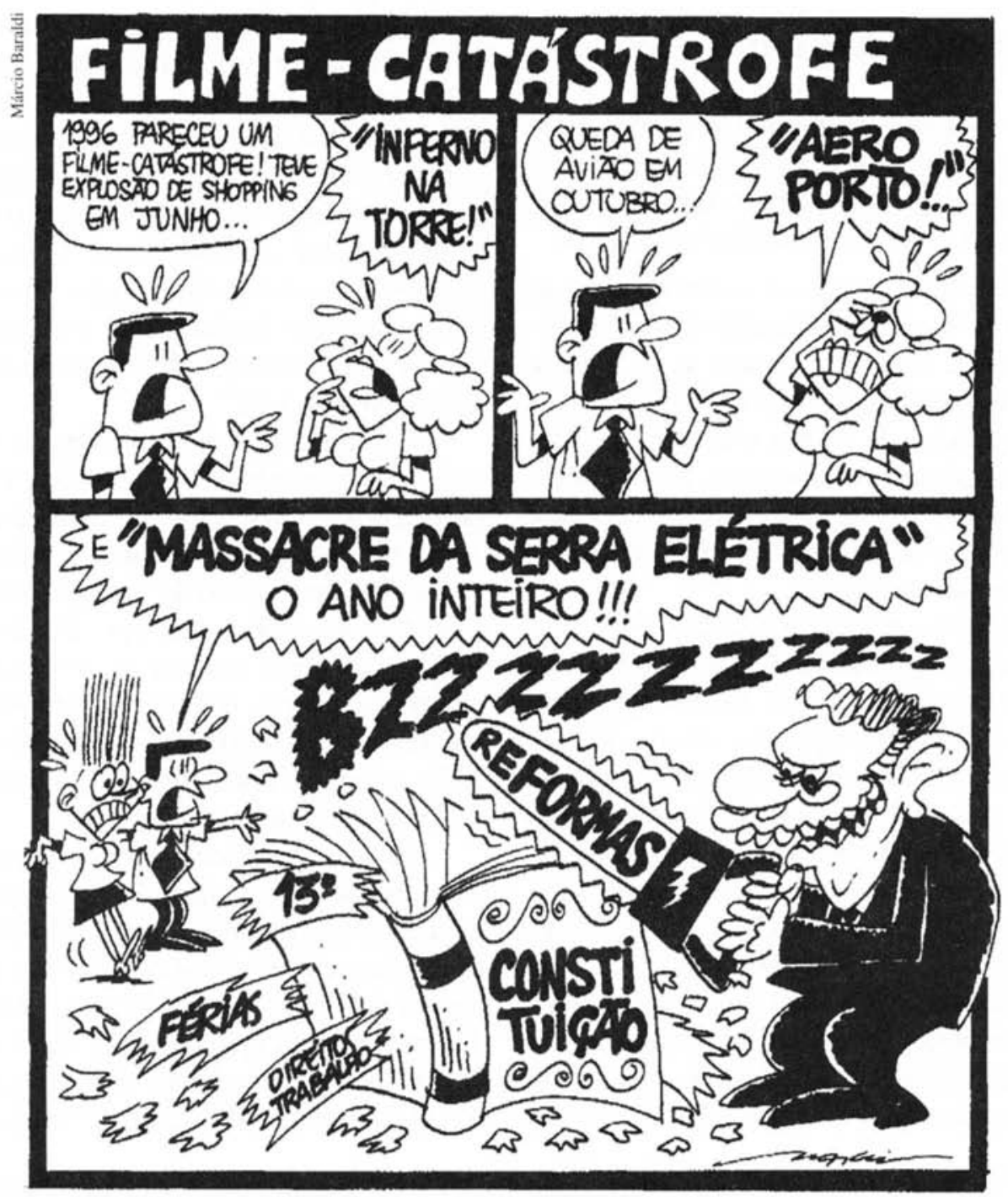

4. LAURELL. Asa Cristina. Avançando em direção ao passado: a política social do neoliberalismo. In: tado e políticas sociais no neoliberalismo. São Paulo: Cortez, 1995. p.151-178. 
Curiosamente, essas análises dão o nome de política social neoliberal àquela política que nega os direitos sociais, que garante o mínimo de sobrevivência aos indigentes, que exige contrapartida para o gozo dos benefícios, que vincula diretamente o nível de vida ao mercado, transformando-o em mercadoria.

\section{CONSEQÜÊNCIAS POLÍTICAS}

Ainda se restringindo a essas poucas falsas polêmicas por motivo de espaço, é indispensável atentar para as conseqüências políticas da supressão dos direitos sociais:

a) Tidas como naturais e independentes, as leis da economia lamentavelmente transmitem a impressão de que se extinguem as sociedades, sobrevivendo apenas os mercados e os grupos unidos a eles. Em conseqüência, arruínam-se as classes sociais, os movimentos sociais, as teorias e o próprio pensamento, no mundo em incontrolável mudança.

b) O processo produtivo submete-se intensamente ao capitalismo financeiro: este acumula mais lucro com a especulação do que com a produção. Ao mesmo tempo, internacionalizam-se a criação e a difusão das indústrias de comunicação, tornando a "globalização econômica" uma crescente "americanização" da cultura de massa.

c) Os "ajustes estruturais" ou a "livre circulação dos capitais" debilitam os processos produtivos das sociedades, sujeitando-as às aventuras do capitalismo financeiro e à "americanização" da cultura. Além do mais, convertem o centro do capitalismo em imitador da América Latina quanto à exclusão, transformando a periferia latino-americana em monumento de pobreza mundial. Eric Hobsbawn, em seu Era dos extremos - $\mathrm{O}$ breve século $\mathrm{XX}^{5}$, coloca o Brasil na posição de "candidato a campeão mundial de desigualdade econômica", de "monumento de injustiça social" e de "monumento à negligência social", aliás por razões conhecidas de todos.

Alain Touraine ${ }^{6}$, capaz de descrições tão esclarecedoras do quadro aqui apresentado, fala em artigo recente da combinação entre liberalismo econômico e nacionalismo cultural, sob a égide de "novos regimes autoritários" ou de "certo nacionalismo autoritário". Para ele, a China indica "uma abertura econômica controlada" e não "um liberalismo de cunho democrático" por causa sobretudo das "ameaças de implosão que pesam sobre esse país".

Em países periféricos como o Brasil, tais "ajustes estruturais" ou a "livre circulação dos capitais" podem eventualmente conduzir a soluções políticas de cunho autoritário, em detrimento da vocação democrática da sociedade brasileira. De qualquer forma, não deve realizar-se em lugar nenhum o que Alain Touraine considera o "fenômeno mais importante do início do século XXI, ou seja, a consolidação e o triunfo de novos regimes autoritários"?.

No caso brasileiro, depois da extinção dos direitos sociais, quem sabe se não chegará a vez de fraquejarem o Estado de direito e o regime democrático-liberal, mais ou menos na linha de pensamento de Alain Touraine? A tradição histórica do Brasil revela constante intervenção estatal no âmbito da política social, alicerçada ao longo do sé-

5. HOBSBAWN, Eric. Era dos Extremos - o breve século XX: 1914-1991. 2.ed. São Paulo: Companhia das Letras, 1996. p.397-555.

6. TOURAINE, Alain. A desforra do mundo político. Folha de S. Paulo. 16 de junho, 1996. p.5/11.

7. Idem. Ibidem. 
culo $\mathrm{XX}$ em direitos sociais variados e gradativamente conquistados.

A política econômica brasileira é exemplar neste aspecto: mesmo em ocasiões de negação explícita de sua presença na economia, o Estado funciona como salvaguarda e como propulsor dos detentores de capital.

Resumo: O autor trata das politicas sociais e dos direitos sociais no Brasil subordinados aos interesses das classes dirigentes, as quais, entre a promulgação de uma Constituição e a imediata proclamação de sua reforma, submetem-se às pressōes de fora. Classifica como maniqueístas as análises que se restringem ao confronto do Estado de bemestar liberal com o Estado de bem-estar social-democrata, mostrando que este (o bemestar social-democrata) só poderia ocorrer nos países centrais. Ressalta a importância de o Estado assegurar os direitos sociais contidos na Constituição de 1988.

Palavras-chave: direitos sociais, política social, Constituição, social-democracia, neoliberalismo
Agora, nesta etapa de desemprego em massa e de privações ilimitadas, a intervenção estatal é imprescindível para concretizar os direitos sociais contidos na Constituição de 1988, visando a construir e a afiançar a segurança social no Brasil, e não o Estado de bem-estar social que o passado não concretizou aqui. Basta conhecer um pouco de história.

Abstract: The author discusses social policies and social rights in Brazil, which are subordinated to the interests of the ruling classes. Between the promulgation of a constitution and the immediate proclaiming of its reform those classes submit themselves to pressures coming from abroad. He also classifies as manichaean the analyses that are restricted to the confrontation between the liberal well-fare State and the social-democrat well-fare State. He points out the importance of the State in insuring the social rights included in the Constitution of 1988.

Key-words: social rights, social policies, Constitution, social-democracy, neoliberalism 